\title{
BƯỚC ĐẦU NGHIÊN CÚU PHÂN LẬP XANTHON TỬ VỎ CÂY BỨA DELPY \\ (GARCINIA DELPYANA PIERRE)
}

\section{Initial research isolating Xanthone of the brark of Garcinia delpyana Pierre}

Ngày nhận bài: 03/01/2017; ngày phản biện: 22/2/2017; ngày duyệt đăng: 22/3/2017

\section{Ngũ Trường Nhân, Nguyễn Thị Phương Thùy* TÓM TẮT}

Bài viết là kết quả bước đầu phân lập các hợp chất Xanthon từ cao chiết eter dầu hỏa của vỏ cây Bứa Garcinia delpyana Pierre thu hái ở đảo Phú Quốc, tỉnh Kiên Giang. Bằng phương pháp SKC kết hợp với SKBM trên silica gel, RP-18 và Sephadex LH-20 trên hệ dung môi eter dầu hỏa - aceton thu được 7 phân đoạn.

Khảo sát, nghiên cứu phân đoạn 4 , sử dụng các phương pháp phổ nghiệm hiện đại $\left({ }^{1} \mathrm{H}\right.$ và ${ }^{13} \mathrm{C}$ NMR, HSQC, HMBC và UV), chúng tôi đã phân lập và xác định được cấu trúc của 1 hợp chất có tên là cowanin thuộc nhóm hợp chất Xanthon.

Từ khóa: Búa Delpy (Garcinia delpyana); họ Măng cụt; phân lậ; xác định cấu trúc; Xanthon

\section{ABSTRACT}

Study on the chemical constituents of a petroleum ether extract of the bark of Garcinia delpyana collected in Phu Quoc Island, a xanthone was isolated. Their structures was determined on the basis of analysis of spectral evidences, including ${ }^{1} \mathrm{H},{ }^{13} \mathrm{C}-\mathrm{NMR}$.

Keywords: Garcinia delpyana; Guttiferae; xathone; cowanin

\section{Mở đầu}

Bứa Delpy có tên khoa học là Garcinia delpyana Pierre, thuộc họ Măng cụt (còn gọi là họ Bứa, Guttiferae hay Clusiaceae), thuộc loại đại mộc, cao đến $10 \mathrm{~m}$, có nhiều mủ màu vàng. Lá có phiến tròn dài thon, chót có mũi, màu sét mặt dưới, gân phụ khít nhau. Hoa đực có từ 58 cánh hoa, tiểu nhụy nhiều trên một đế lồi. Hoa lưỡng tính đơn độc. Quả có mũi dài 5-7 mm, 6-7 buồng và 6-7 hạt, quả bì xốp vàng, hột cong dài $1.6 \mathrm{~cm}[1]$.

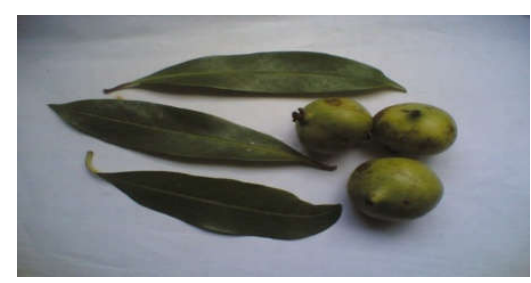

Hình 1. Hình ảnh lá và quả bứa Garcinia delpyana Pierre thu hái ở đảo Phú Quốc
Bứa Delpy được dùng để nhuộm màu vàng hơi đỏ cho vải sợi, gỗ dùng để đóng đồ dùng. Trong dân gian người ta dùng vỏ cây trị tiêu chảy [1]. Các nghiên cứu về hóa học của một số loài từ Chi này trên thế giới cho thấy sự hiện diện phong phú các xanthon, benzoquinon, terpen và một số ít các lớp chất khác [2,8].

Thành phần hóa học của bứa Delpy chưa được nghiên cứu ở Việt Nam cũng như trên thế giới. Chính vì vậy việc nghiên cứu thành phần hóa học là cấp thiết góp phần làm sáng tỏ cơ sở khoa học về các tác dụng chữa bệnh theo phương thức cổ truyền.

\section{2. Đối tượng và phương pháp nghiên cứu}

\section{1. Đối tượng nghiên cứu}

Trong đề tài này chúng tôi khảo sát thành phần hóa học cao eter dầu hỏa của vỏ 
bứa Delpy (Garcina delpyana Pierre) thu hái ở đảo Phú Quốc, tỉnh Kiên Giang.

\subsection{Phương pháp nghiên cứu}

Sử dụng phương pháp thực nghiệm gồm:

- Phổ cộng hưởng từ hạt nhân ghi trên máy Bruker AV $500\left[500 \mathrm{MHz}\left({ }^{1} \mathrm{H}\right)\right.$ và 125 $\mathrm{MHz}\left({ }^{13} \mathrm{C}\right)$ ] với $\mathrm{TMS}$ là chất nội chuẩn và $\mathrm{CDCl}_{3}$ hay aceton- $d_{6}$ là dung môi.

- SKBM được thực hiện trên bảng silica gel của Merck. Các cấu tử trên bản mỏng được phát hiện bằng đèn tử ngoại hay bằng hơi iod hoặc dung dịch $\mathrm{FeCl}_{3}$ trong metanol (để phát hiện các hợp chất phenol).

- SKC được thực hiện trên silica gel của Merck, RP-18 của Merck, SKC lọc bằng gel được thực hiện trên Sephadex LH-20.

- Phương pháp cô lập: sử dụng SKC kết hợp với SKBM. Phân đoạn nào cho vệt rõ rệt dưới đèn UV hay hơi iod sẽ được chọn để khảo sát tiếp.

\section{Kết quả và thảo luận}

Sắc ký cột phân đoạn 4 với nhiều hệ dung ly khác nhau trên silica gel và RP-18 kết hợp với sắc ký cột lọc trên Sephadex LH-20, chúng tôi đã cô lập được hợp chất cowanin có mã số GD2.

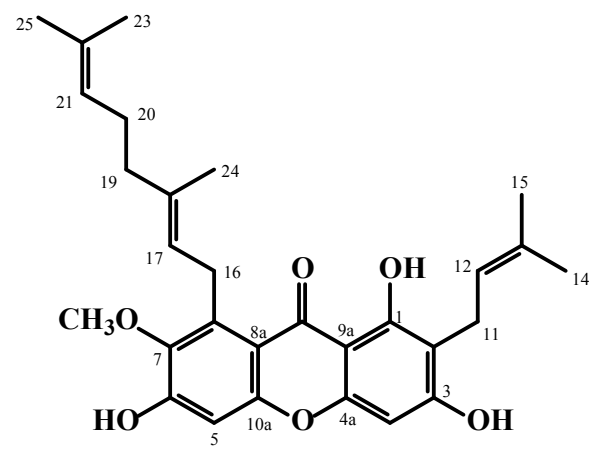

\section{Hình 2: Cấu trúc hóa học của (GD2)}

Cowanin (GD2) thu được dưới dạng nhựa màu vàng, cho phản ứng dương tính với dung dịch $\mathrm{FeCl}_{3}$ trong metanol nên cũng là một dẫn xuất phenol. Phổ UV $\left(\lambda_{\max } 243,262\right.$, 315 và $360 \mathrm{~nm}$ ) tương tự phổ UV của khung xanthon tetraoxygen trí hoán.
Phổ ${ }^{1} \mathrm{H}$ NMR cho tín hiệu cộng hưởng ứng với một nhóm - $\mathrm{OH}$ kiềm nối $\left[\delta_{\mathrm{H}} 13.78(1 \mathrm{H}, \mathrm{s}, 1\right.$ $\mathrm{OH}$ ], hai nhóm $-\mathrm{OH}$ tự do $\left[\delta_{\mathrm{H}} 6.43\right.$ và 6.37 (mỗi mũi $1 \mathrm{H}$, br $\mathrm{s}, 3-\mathrm{OH}$ và $6-\mathrm{OH}]$, hai vòng benzen ngũ hoán $\left[\delta_{\mathrm{H}} 6.81(1 \mathrm{H}, \mathrm{s}, \mathrm{H}-5)\right.$ và $6.28(1 \mathrm{H}, \mathrm{s}, \mathrm{H}-$ 4)], một nhóm isoprenyl [ $\delta_{\mathrm{H}} 5.27(1 \mathrm{H}, \mathrm{m}, \mathrm{H}-12)$, $3.44\left(2 \mathrm{H}, \mathrm{d}, J=6.5 \mathrm{~Hz}, \mathrm{H}_{2}-11\right), 1.82\left(3 \mathrm{H}, \mathrm{s}, \mathrm{H}_{3}-14\right)$ và $\left.1.76\left(3 \mathrm{H}, \mathrm{s}, \mathrm{H}_{3}-15\right)\right]$, một nhóm $(E)-3,7-$ dimetyl-2,6-octadienyl hay geranyl $\left[\delta_{\mathrm{H}} 5.27(1 \mathrm{H}\right.$, m, H-17), 5.03 (1H, m, H-21), 4.09 (2H, d, $J=5.5$ $\left.\mathrm{Hz}, \mathrm{H}_{2}-16\right), 2.00-2.05$ (4H, m, $\mathrm{H}_{2}-19$ và $\mathrm{H}_{2}-20$ ), $1.84\left(3 \mathrm{H}, \mathrm{s}, \mathrm{H}_{3}-24\right), 1.60\left(3 \mathrm{H}, \mathrm{s}, \mathrm{H}_{3}-25\right)$ và 1.54 $\left.\left(3 \mathrm{H}, \mathrm{s}, \mathrm{H}_{3}-23\right)\right]$ và một nhóm metoxyl $\left[\delta_{\mathrm{H}} 3.80\right.$ $\left.\left(3 \mathrm{H}, \mathrm{s}, 7-\mathrm{OCH}_{3}\right)\right]$.

Phổ DEPT 90 và DEPT 135 cho biết GD2 có năm nhóm $\mathrm{CH}$, bốn nhóm $\mathrm{CH}_{2}$, năm nhóm $\mathrm{CH}_{3}$ và một nhóm $-\mathrm{OCH}_{3}\left(\delta_{\mathrm{C}} 62.0\right)$.

Phổ ${ }^{13} \mathrm{C}$ NMR cho các mũi cộng hưởng ứng với 29 carbon trong đó có năm mũi cộng hưởng của nhóm isoprenyl $\left[\delta_{\mathrm{C}} 135.4(\mathrm{~s}, \mathrm{C}-13)\right.$, 121.6 (d, C-12), 25.8 (q, C-15), 21.4 (t, C-11) và $16.5(\mathrm{q}, \mathrm{C}-14)]$, mười tín hiệu cộng hưởng của nhóm geranyl $\left[\delta_{\mathrm{C}} 135.5(\mathrm{~s}, \mathrm{C}-18), 131.3\right.$ (s, C-22), 123.3 (d, C-21), 124.3 (d, C-17), 39.7 (t, C-19), 26.5 (t, C-20), 25.6 (q, C-25), 17.9 (q, C-23) và 17.6 (q, C-24)]. Ngoài ra còn có các tín hiệu cộng hưởng của khung xanthon bao gồm một nhóm carbonyl tiếp cách $\left[\delta_{\mathrm{C}}\right.$ 182.0 (s, C-9)] và mười hai carbon hương phương với sáu carbon mang oxygen $\left[\delta_{\mathrm{C}} 161.6\right.$ (s, C-3), 160.6 (s, C-1), 155.8 (s, C-6), 155.0 (s, C-4a), 154.6 (s, C-10a) và $142.7(\mathrm{~s}, \mathrm{C}-7)]$, bốn carbon trí hoán $\left[\delta_{\mathrm{C}} 137.2(\mathrm{~s}, \mathrm{C}-8), 112.2\right.$ $(\mathrm{s}, \mathrm{C}-8 \mathrm{a}), 108.6(\mathrm{~s}, \mathrm{C}-2)$ và $103.6(\mathrm{~s}, \mathrm{C}-9 \mathrm{a})]$ và hai carbon mang proton $\left[\delta_{C} 101.6(\mathrm{~d}, \mathrm{C}-5)\right.$ và $93.2(\mathrm{~d}, \mathrm{C}-4)]$.

Kết hợp các dữ liệu phổ trên và so sánh với tham khảo cho thấy GD2 là $(E)-1,3,6-$ trihydroxy-7-metoxy-8-(3,7-dimetylocta-2,6dienyl)-2-(3-metylbut-2-enyl)xanthon hay cowanin, đã được tìm ra trước đây từ $G$. cowa [9] và G. schomburgkiana [10]. 
Bảng 1: Số liệu phổ ${ }^{1} H$ và ${ }^{13} \mathrm{C}$ NMR của GD2 (cowanin)

\begin{tabular}{|c|c|c|c|c|c|}
\hline Vị trí & $\boldsymbol{\delta}_{\mathbf{H}}$ & $\boldsymbol{\delta}_{\mathbf{C}}$ & $\mathbf{V i ̣ ~ t r i ́ ~}$ & $\boldsymbol{\delta}_{\mathbf{H}}$ & $\boldsymbol{\delta}_{\mathbf{C}}$ \\
\hline 1 & & 160.6 & 14 & $1.82 \mathrm{~s}$ & 16.5 \\
\hline 2 & & 108.6 & 15 & $1.76 \mathrm{~s}$ & 25.8 \\
\hline 3 & & 161.6 & 16 & $4.09 \mathrm{~d}(5.5)$ & 26.6 \\
\hline 4 & $6.28 \mathrm{~s}$ & 93.2 & 17 & $5.27 \mathrm{~m}$ & 124.3 \\
\hline $4 \mathrm{a}$ & & 155.0 & 18 & & 135.5 \\
\hline 5 & $6.81 \mathrm{~s}$ & 101.6 & 19 & $2.00-2.05 \mathrm{~m}$ & 39.7 \\
\hline 6 & & 155.8 & 20 & $2.00-2.05 \mathrm{~m}$ & 26.5 \\
\hline 7 & & 142.7 & 21 & $5.03 \mathrm{~m}$ & 123.3 \\
\hline 8 & & 137.2 & 22 & & 131.3 \\
\hline $8 \mathrm{a}$ & & 112.2 & 23 & $1.54 \mathrm{~s}$ & 17.9 \\
\hline 9 & & 182.0 & 24 & $1.84 \mathrm{~s}$ & 17.6 \\
\hline $9 \mathrm{a}$ & & 103.6 & 25 & $1.60 \mathrm{~s}$ & 25.6 \\
\hline $10 \mathrm{a}$ & & 154.6 & $1-\mathrm{OH}$ & $13.78 \mathrm{~s}$ & \\
\hline 11 & $3.44 \mathrm{~d}(6.5)$ & 21.4 & $3 \mathrm{và} 6-\mathrm{OH}$ & 6.43 và $6.37 \mathrm{br} \mathrm{s}$ & \\
\hline 12 & $5.27 \mathrm{~m}$ & 121.6 & $7-\mathrm{OCH}$ & $3.80 \mathrm{~s}$ & 62.0 \\
\hline 13 & & 135.4 & \multicolumn{3}{c}{} \\
\hline
\end{tabular}

\section{Kết luận - đề xuất}

Bước đầu nghiên cứu phân lập Xanthon từ vỏ cây bứa Garcinia delpyana Pierre, sử dụng các phương pháp phổ nghiệm hiện đại $\left({ }^{1} \mathrm{H}\right.$ và
${ }^{13} \mathrm{C} \mathrm{NMR}, \mathrm{HSQC}, \mathrm{HMBC}$ và UV), chúng tôi đã phân lập và xác định được cấu trúc của 1 hợp chất có tên là cowanin thuộc nhóm hợp chất Xanthon.

\section{TÀI LIỆU THAM KHẢO}

1. Phạm Hoàng Hộ (1999), Cây cỏ Việt Nam, Quyển I, NXB Trẻ, Tp. HCM.

2. Đỗ Tất Lợi (1995), Nhũng cây thuốc và vị thuốc Việt Nam, NXB Khoa học và Kỹ thuật, Tp. Hồ Chí Minh.

3.Võ Văn Chi (1997), Tù điển cây thuốc Việt Nam, NXB Y học, Tp. Hồ Chí Minh.

4. Peres V., Nagem T. J., De Oliveira F. F. (2000) Tetraoxygenated naturally occurring xanthones, Phytochemistry, 55, 683-710.

5. Bennett G. J., Lee H.-H. (1989), Xanthones from Guttiferae, Phytochemistry, 28 (4), 967-998.

6. Kumar P., Baslas R. K. (1980), Phytochemical and biological studies of the plants of genus Garcinia, Herba Hungarica, 19 (1), 81-91.

7. Negi P. S., Javaprakasha G. K., Jena B. S. (2008), Antibacterial activity of the extracts from the fruit rinds of Garcinia cowa and Garcinia pedunculata against food borne pathogens and spoilage bacteria, LWT-Food Sci. Tech., 41, 1857-1861.

8. Bennett G. J., Lee H. H. (1989), Review: Xanthones from Guttiferae, Phytochemistry, 28, 967-998.

9. Na Pattalung P., Thongtheeraparp W., Wiriyachitra P., Taylor, W. C. (1994), Xanthones of Garcinia cowa, Planta Med., 60, 365-368.

10. Nguyễn Thị Ngọc Tuyết (2002), Khảo sát thành phần hóa học của vỏ cây bưa đồng Garcinia schomburgkiana, Luận văn Thạc sĩ, Khoa Hóa, Trường Đại học Khoa Học Tự Nhiên Tp. HCM. 